Artigo original

Hegemonia - Revista Eletrônica de Relações Internacionais do Centro Universitário Unieuro

ISSN: $1809-1261$

UNIEURO, Brasília, número Especial, 2016, pp. 46-75.

Recebido em: 26/8/2016

Avaliado em: 12/9/2016

Aprovado em: 6/10/2016

\title{
Demanda por Moeda no Brasil: A Evidência dos Testes de Cointegração e de Estabilidade
}

José Coelho Matos Filho ${ }^{1}$

Resumo: Neste artigo usamos dados trimestrais para estimar uma equação de demanda por moeda para o Brasil, entre 1980 e 2010. O resultado indica a estabilidade dos parâmetros da equação estimada, alcançada com a inclusão de um vetor de variáveis dummy, representando as inovações financeiras.

Palavras-chave: Demanda por moeda; Política monetária; Séries temporais.

Abstract: In this paper we use quarterly data to estimate a money demand equation for Brazil between 1980 and 2010. The result indicates the stability of estimated parameters of the equation obtained with the inclusion of a vector of dummy variables representing financial innovations.

Key-words: Demand for money; Monetary policy; Time series.

JEL Classification: E41; E52; C32.

1 Doutor em Economia, Docente do Departamento de Teoria Econômica da Universidade Federal do Ceará. 
Artigo original

Hegemonia - Revista Eletrônica de Relações Internacionais do Centro Universitário Unieuro

ISSN: $1809-1261$

UNIEURO, Brasília, número Especial, 2016, pp. -.

\section{Introdução}

Por que um indivíduo racional demanda moeda, se é possível manter riqueza em ativos que rendem juros? A resposta, contida em HICKS (1935), indica que a razão para isso é que os custos de transformar outros ativos em moeda, em períodos curtos de tempo, são muito altos. Nesse caso, o melhor que o indivíduo pode fazer é reter alguma quantidade de saldos reais, para fazer frente à necessidade de efetuar transações. Apesar disso, apenas em SIDRAUSKI (1967) a demanda por moeda foi encarada como a solução de um problema de alocação de riqueza, em que os saldos monetários reais fazem parte do conjunto de argumentos da função utilidade, gerando satisfação pelo comando que exercem sobre o consumo de bens ${ }^{2}$. O problema dessa abordagem, conhecida como money in the utility function, é justificar a demanda por um pedaço de papel, com custo marginal nulo ou quase nulo. Uma forma de resolver tal problema é admitir que a posse de saldos reais influencie a quantidade de tempo que o indivíduo dedica ao lazer. Isto é, justifica-se, indiretamente, o aumento de satisfação do indivíduo pela posse de moeda. Essa abordagem, conhecida como shopping time ou transaction costs é devida, inicialmente, a SAVING (1971). Outra abordagem influente que, nessa mesma direção, justifica a retenção de saldos reais é o modelo cash-in-advance [CLOWER (1967), LUCAS (1980)], em que a posse de moeda gera satisfação pelo comando que exerce na aquisição de bens de consumo.

2 Até as décadas de 1950 e 1960, apesar da constatação de Hicks, as discussões sobre a demanda por moeda centraram-se no do conceito de velocidade renda da moeda e de sua estabilidade, com a abordagem keynesiana da demanda especulativa impondo a variabilidade da velocidade da moeda e, como consequência, da própria 
Artigo original

Hegemonia - Revista Eletrônica de Relações Internacionais do Centro Universitário Unieuro

ISSN: $1809-1261$

UNIEURO, Brasília, número Especial, 2016, pp. -.

Todas essas abordagens têm denominadores comuns: em equilíbrio, a função demanda por moeda depende de uma variável de escala (consumo, renda ou riqueza, etc) e de um custo de oportunidade de reter dinheiro (taxa de juros, inflação esperada), além de as três abordagens resultar em uma mesma forma testável para a função demanda por moeda ${ }^{3}$.

O parágrafo anterior nos leva a concluir que, no que se refere à forma funcional da demanda por moeda, o debate em teoria monetária acabou. Apesar disso, não há consenso sobre qual é a melhor definição de moeda a ser utilizada e quais as variáveis ou argumentos que devem compor a função demanda por moeda. No primeiro caso, porque o que passa por moeda pode rapidamente modificar-se como resultado dos arranjos do sistema financeiro [GOLDFELD $(1973,1976)$ e GOLDFELD \& SICHEL (1990)] e no segundo caso, porque das escolhas corretas da variável de escala e do custo de oportunidade, muitas vezes, depende a estabilidade temporal dos parâmetros estimados da demanda por moeda [GOLDFELD \& SICHEL (1990)]. ${ }^{4}$

demanda por moeda, enquanto a escola monetarista pregava sua estabilidade, no sentido de a demanda por moeda ser previsível.

3 A esse respeito, ver MATOS FILHO (2008).

4 O uso de variáveis de escala apropriadas na estimação da demanda por moeda tem tido uma linha de pesquisa bem delineada na literatura econômica. Por exemplo, HOWELLS \& HUSSEIN (1997) postularam que as transações totais de em uma economia em determinado período são mais apropriadas como proxy para a variável de escala, uma vez que, diferentemente do PNB, incluem transações ali não contempladas (vendas de bens intermediários, compras de bens pré-existentes, transações financeiras, etc). Outros, como MANKIW \& SUMMERS (1986), partindo da separação do PNB em componentes que geram diferentes necessidades de pagamento, concluem que o consumo é mais intensivo em moeda do que os outros componentes. 
Hegemonia - Revista Eletrônica de Relações Internacionais do Centro Universitário Unieuro

ISSN: $1809-1261$

UNIEURO, Brasília, número Especial, 2016, pp. -.

Aliem-se a isso as inovações financeiras ocorridas nas últimas quatro décadas e o resultado é, muitas vezes, equações de demanda por moeda que superestimam (ou subestimam) as necessidades de saldos reais dos indivíduos, sugerindo descartá-las como mecanismos de previsão da demanda por saldos reais, a não ser que tais inovações sejam incorporadas nas especificações da demanda por moeda, apontando a cointegração das variáveis que compõem os seus argumentos e sugerindo a existência de equilíbrio no longo prazo, como postula ENGLE \& GRANGER (1987). Além disso, há, ainda, outro problema a resolver: a incorporação das inovações financeiras na especificação da equação de demanda por moeda torna seus parâmetros estruturalmente estáveis? Essa perspectiva nos levou a pesquisar, com base nos testes de cointegração e de estabilidade, se existe demanda trimestral por moeda no Brasil, no período compreendido entre janeiro de 1980 e junho de 2010.

O trabalho está dividido em duas partes, além dessa introdução. $\mathrm{Na}$ segunda parte analisa-se a demanda por moeda no período considerado e na terceira, à guisa de conclusão, os resultados são discutidos.

2. A Demanda por Moeda no Brasil no Período 1980-2010

A função demanda por moeda diz respeito, principalmente, à demanda por liquidez. Nesse contexto, é razoável que algumas formulações conduzam a definições de moeda menos amplas, incluindo, por vezes, 
Artigo original

Hegemonia - Revista Eletrônica de Relações Internacionais do Centro Universitário Unieuro

ISSN: $1809-1261$

UNIEURO, Brasília, número Especial, 2016, pp. -.

apenas moeda manual e depósitos à vista nos bancos ${ }^{5}$. Além disso, modelos testados na literatura relevante [IRELAND (1995), ARRAU \& DE GREGORIO (1993)] têm deduzido funções demanda por moeda estrita. Nesse contexto, a análise aqui proposta é conduzida no sentido de avaliar o comportamento trimestral da demanda real por $M 1$, no período que vai do primeiro trimestre do ano de 1980 ao quarto trimestre de 2010.

A escolha do período foi induzida pela riqueza factual envolvendo aspectos institucionais na economia brasileira. De fato, há razões suficientes para suspeitar da ocorrência de mudanças na função demanda por moeda, a partir do início da década de 1980: suspeita-se de que o choque do petróleo de 1979 e os choques agrícolas de 1979 e 1983, aliados à indexação generalizada, levaram à persistência da inflação, a despeito da queda do produto real. Adicionalmente, enquanto no início da década dos anos de 1980, a crise da dívida externa obrigava o país a gerar os saldos comerciais necessários ao pagamento do seu serviço, tais saldos se convertiam em aumentos de oferta de moeda ou em crescimento da dívida interna, impondo taxas de juros maiores e levando ao rápido desenvolvimento do setor financeiro não monetário. Nesse caso, qualquer formulação apropriada para a função demanda por moeda no Brasil deve incorporar variáveis que captem tais fenômenos, aqui caracterizados por um vetor de variáveis dummy correspondentes

\footnotetext{
5 Para LAIDLER (1999), na construção de uma medida empírica de moeda, deve-se levar em conta que o papel de meio de troca domina os papeis de reserva de valor e unidade de conta. Além disso, o problema com o uso de agregados monetários mais amplos é o envolvimento, na sua definição, de componentes que não podem ser explicados pelos mesmos fatores, como por exemplo, papel moeda em poder do público e depósitos a prazo [BATTEN \& THORNTON (1983)].
} 
Hegemonia - Revista Eletrônica de Relações Internacionais do Centro Universitário Unieuro

ISSN: $1809-1261$

UNIEURO, Brasília, número Especial, 2016, pp. -.

aos principais eventos ocorridos no período: a crise da dívida mexicana, ocorrida no segundo semestre de 1982; o Plano Cruzado, em fevereiro de 1986; o Plano Bresser, no primeiro semestre de 1987; o Plano Collor, em março de 1990; o Plano Real, de 1994; a crise dos mercados asiáticos, no segundo semestre de 1997; a mudança cambial, em fevereiro de 1999 e o processo eleitoral de 2002.

Como sugerido na introdução, uma possível razão para o comportamento desfavorável da função demanda por moeda tradicional no longo prazo é a falta de cointegração entre as variáveis que compõem os seus argumentos. Assim, um teste que pode (ou não) validar essa perspectiva é o teste de Johansen que, baseado no Teorema de Representação de Granger, investiga a existência de um ou mais vetores de cointegração entre variáveis integradas de mesma ordem.

No nosso estudo testamos para a ordem de integração das variáveis $\log m_{1}, \log$ pib e juros, que correspondem aos logaritmos dos saldos monetários reais $\left(\frac{M 1}{P}\right)$, do PIB real e de uma medida da taxa de juros nominal, representada pela taxa Overselic. ${ }^{6}$ Para isso, é usual começar a análise por testes de estacionariedade apropriados para a verificação da existência de raízes unitárias nas variáveis em nível, uma vez que os testes de cointegração, dentre eles o teste de Johansen, são apropriados para variáveis integradas de mesma ordem. Os testes de

6 Deflacionaram-se as variáveis nominais com o IGP-DI, da FGV. 
Hegemonia - Revista Eletrônica de Relações Internacionais do Centro Universitário Unieuro

ISSN: $1809-1261$

UNIEURO, Brasília, número Especial, 2016, pp. -.

estacionariedade, com resultados contidos no Quadro 1, conduzem à conclusão de que todas as variáveis são não-estacionárias em nível.

Quadro 1

Testes ADF: $1980-2010$

\begin{tabular}{|l|c|c|c|}
\hline \multicolumn{1}{|c|}{ Variável } & $\begin{array}{c}\text { Estatística } \\
\text { ADF }\end{array}$ & $\begin{array}{c}\text { ADF Crítico } \\
(5 \%)\end{array}$ & $\begin{array}{c}\text { ADF Crítico } \\
(1 \%)\end{array}$ \\
\hline $\log m 1(\mathrm{a})$ & $-1,647$ & $-2,887$ & $-3,489$ \\
\hline $\log p i b(\mathrm{~b})$ & $-2,771$ & $-3,450$ & $-4,042$ \\
\hline juros (c) & $-1,026$ & $-1,944$ & $-2,586$ \\
\hline
\end{tabular}

Obs: (a) ADF sem defasagem, com intercepto; (b) PhillipsPerron com quatro defasagens, com intercepto e tendência; (c) ADF sem defasagem, sem intercepto ou tendência.

Tendo concluído pela não estacionariedade, em nível, das variáveis $\log m 1, \log$ pib e juros, o passo seguinte é a repetição dos testes de estacionariedade, em primeiras diferenças, cujos resultados, sumariados no Quadro 2, indicam que todas as variáveis, em nível, são integradas de ordem um, ou I(1), tornando possível a aplicação do teste de cointegração de Johansen para a identificação de vetores de cointegração, cujo resultado, contido no Quadro 3, indica a não rejeição da hipótese nula da não existência de vetor de cointegração, aos níveis de significância de $1 \%$ e $5 \%$, conduzindo à conclusão de que sem a inclusão de alguma variável que represente as inovações financeiras, não há cointegração entre as variáveis que compõem a função demanda por moeda. 
Artigo original

Hegemonia - Revista Eletrônica de Relações Internacionais do Centro Universitário Unieuro

ISSN: $1809-1261$

UNIEURO, Brasília, número Especial, 2016, pp. -.

Testes ADF: $1980-2010$

\begin{tabular}{|l|c|c|c|}
\hline \multicolumn{1}{|c|}{ Variável } & $\begin{array}{c}\text { Estatística } \\
\text { ADF }\end{array}$ & $\begin{array}{c}\text { ADF Crítico } \\
(5 \%)\end{array}$ & $\begin{array}{c}\text { ADF Crítico } \\
(1 \%)\end{array}$ \\
\hline$\Delta m 1$ & $-15,185$ & $-1,944$ & $-2,586$ \\
\hline$\Delta$ pib & $-16,657$ & $-1,944$ & $-2,586$ \\
\hline$\Delta j u r o s$ & $-11,219$ & $-1,944$ & $-2,586$ \\
\hline
\end{tabular}

Obs: ADF sem defasagem, sem intercepto ou tendência.

Quadro 3

Teste de $\log m 1$, $\log$ pibe juros

\begin{tabular}{|c|c|c|c|c|c|}
\hline$H_{0}$ & $H_{1}$ & Autovalor & $\lambda_{\text {traco }}$ & $\begin{array}{c}\text { Valor Crítico } \\
5 \%\end{array}$ & $\begin{array}{c}\text { Valor } \\
\text { Crítico } \\
1 \%\end{array}$ \\
\hline$r=0$ & $r>0$ & 0,0969 & 18,376 & 24,31 & 29,75 \\
\hline$r=1$ & $r>1$ & 0,05861 & 7,406 & 12,53 & 16,31 \\
\hline$r=2$ & $r>2$ & 0,00814 & 0,882 & 3,84 & 6,51 \\
\hline
\end{tabular}

Obs.: (a) VAR com 4 defasagens; (b) Estatísticas do Eviews 5.1.

Uma maneira simples de testar a veracidade do teste de Johansen, é a aplicação, sobre os mesmos dados, do teste de Engle-Granger, que consiste na avaliação da possível estacionariedade dos resíduos da equação de longo prazo, abaixo, cujos resultados, plotados na Figura 1, dão uma ideia da falta de cointegração entre as variáveis. ${ }^{7}$

$\log m 1_{t}=0,9531 \log$ pib $_{t}-0,2052$ juros $_{t}$

$(69,561)$

$(-9,475)$ 
Artigo original

Hegemonia - Revista Eletrônica de Relações Internacionais do Centro Universitário Unieuro

ISSN: $1809-1261$

UNIEURO, Brasília, número Especial, 2016, pp. -.

Figura 1

Resíduos da Equação $\log m 1$ : 1980-2010

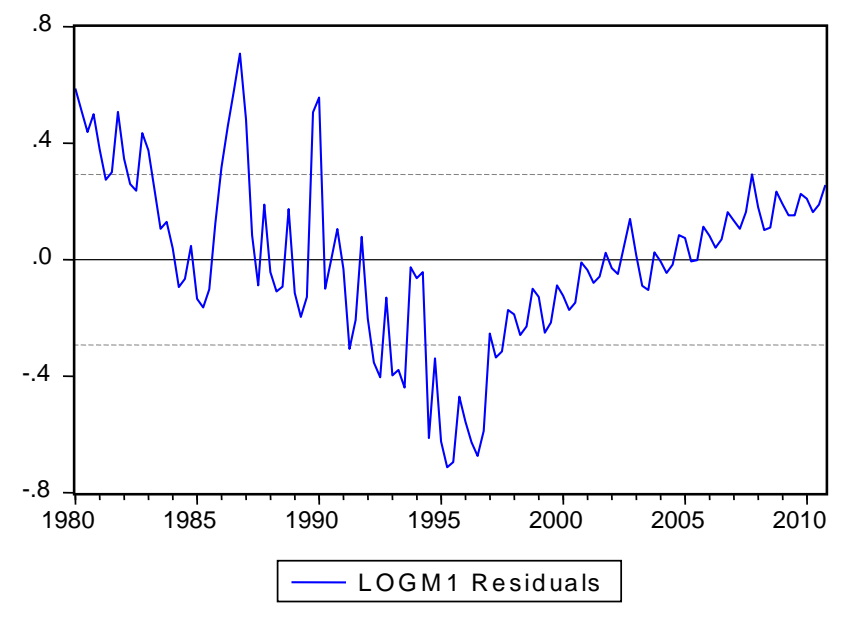

A pergunta que daí emerge é: a introdução de variáveis dummy como proxies para as inovações financeiras ocorridas no período será capaz de apontar a cointegração de $\log m 1, \log$ pib e juros, sugerindo uma relação de equilíbrio de longo prazo?

O problema é, antes de prosseguirmos, responder adequadamente o que é e o que caracteriza uma inovação financeira. A idéia de inovação financeira envolve desde o puro e simples progresso tecnológico facilitador das transações, até as mudanças nos mecanismos de regulação financeira, passando pela capacidade de reação dos agentes econômicos à tomada de posição das autoridades monetárias diante do quadro econômico geral. Empiricamente, considera-se inovação financeira tudo que desloque permanentemente a função demanda por

7 Um teste ADF aplicado aos resíduos da equação rejeitam a hipótese de estacionariedade dos mesmos ao nivel de significância de $5 \%$. 
Artigo original

Hegemonia - Revista Eletrônica de Relações Internacionais do Centro Universitário Unieuro

ISSN: $1809-1261$

UNIEURO, Brasília, número Especial, 2016, pp. -.

moeda e que não tenha explicação nos movimentos da variável de escala ou do custo de oportunidade de reter moeda [ARRAU \& DE GREGORIO (1993)]. Por exemplo, as melhoras nas técnicas de administração de caixa pelas firmas são bons exemplos de inovações financeiras: pela concentração de recursos em contas únicas e/ou pelo controle de desembolsos, as firmas reduzem os custos de transação e as incertezas do fluxo de caixa, alterando permanentemente sua retenção de saldos reais.

É importante notar que embora as inovações financeiras reflitam, em grande parte, melhoras exógenas decorrentes de avanços nas tecnologias de computação e de telecomunicação, refletem também escolhas endógenas das firmas. Por exemplo, os altos custos de oportunidade de reter moeda induzem as firmas a investir em novas tecnologias de transação, como se estivessem engajadas em projetos de investimento [GOLDFELD (1976)]. Assim, uma vez que a decisão de inovar é tomada, não há como voltar atrás se a taxa de juros cair abaixo de um patamar prévio [IRELAND (1995)]. Portanto, a idéia de usar variáveis dummy (de efeito permanente) como proxies das inovações financeiras representa um esforço de modelagem de choques que têm efeitos permanentes na demanda por moeda.

Com isso em mente, o método de Johansen foi novamente aplicado incluindo, para representar os picos da taxa de juros ${ }^{8}$, variáveis representativas da crise da dívida externa dos países em desenvolvimento iniciada com a crise do México, em fins de 1982; dos

8 A utilização dos picos da taxa de juros como proxies para as inovações financeiras foi consagrada em GOLDFELD (1976) e GOLDEFELD \& SICHEL (1990), sugerindo que 
Artigo original

Hegemonia - Revista Eletrônica de Relações Internacionais do Centro Universitário Unieuro

ISSN: $1809-1261$

UNIEURO, Brasília, número Especial, 2016, pp. -.

planos Cruzado, Bresser, Collor e Real; da crise dos mercados de capitais iniciada nos países da Ásia, ocorrida no segundo semestre de 1997 e da mudança da política cambial brasileira, ocorrida em fevereiro de $1999^{9}$, além dos distúrbios causados pelo processo eleitoral do ano de 2002, como variáveis dummy de efeito permanente fora do espaço de cointegração ${ }^{10}$, com o seguinte resultado:

\section{Quadro 4}

Teste de Cointegração de $\log m 1$, $\log$ pibe juros

\begin{tabular}{|c|c|c|c|c|c|}
\hline$H_{0}$ & $H_{1}$ & Autovalor & $\lambda_{\text {trąo }}$ & $\begin{array}{c}\text { Valor Crítico } \\
5 \%\end{array}$ & $\begin{array}{c}\text { Valor } \\
\text { Crítico } \\
1 \%\end{array}$ \\
\hline$r=0$ & $r>0$ & 0,4409 & $49,5630^{* *}$ & 24,31 & 29,75 \\
\hline$r=1$ & $r>1$ & 0,0541 & $15,2830^{*}$ & 12,53 & 16,31 \\
\hline$r=2$ & $r>2$ & 0,0249 & 0,9606 & 3,84 & 6,51 \\
\hline
\end{tabular}

Obs.: (a) VAR com 6 defasagens; (b) * Indica a rejeição da hipótese nula ao nível de significância de $5 \%$;

(c) **Indica a rejeição da hipótese nula ao nível de significância de $1 \%$.

- que indica a existência de um vetor de cointegração que, após normalização, sugere a seguinte equação de longo prazo para a demanda por saldos reais:

as altas taxas nominais de juros provocam uma espécie de 'efeito catraca' (ratchet effect) na demanda por moeda.

9 A inspeção visual da série completa não permite a visualização dos picos das taxas de juros. No entanto, procedimento de cortes amostrais, de modo a tomar subamostras mais homogêneas, permitem reconhecer tais picos. 
Artigo original

Hegemonia - Revista Eletrônica de Relações Internacionais do Centro Universitário Unieuro

ISSN: $1809-1261$

UNIEURO, Brasília, número Especial, 2016, pp. -.

$\log m 1_{t}=\underset{(0,1511)}{1,0508} \log$ pib $_{t}-\underset{(0,0202)}{0,1280}$ juros $_{t}$

$\mathrm{Na}$ equação estimada, os valores entre parênteses remetem aos desvios-padrão (assintóticos) e os coeficientes das variáveis log pib e juros têm sinais plausíveis, embora aponte o coeficiente da variável $\log$ pib maior do que a unidade, o que, em tese, contraria a ideia de que, no longo prazo, a elasticidade-renda da demanda por moeda tem de ser igual a um. No entanto, como notou BOFINGER (2001), esse aparente enigma demonstra apenas que a participação dos ativos financeiros na riqueza total está crescendo mais rapidamente do que a participação do PIB real, uma possibilidade razoável quando se trata da economia brasileira nos anos de 1980 e metade dos anos de 1990.

Como é praxe, a título de corroboração, aplicamos sobre os dados o teste de Engle-Granger - incluindo na especificação do modelo as variáveis dummy antes referidas - com um resultado que aponta a cointegração entre as variáveis $\log m_{1}, \log$ pib e juros, ao sugerir erros estacionários para a estimativa de $\log m_{1}{ }^{11}$ (Figura 2), com a rejeição da hipótese nula de não estacionariedade dos mesmos, ao nível de significância de $1 \%$.

10 Como a inclusão de dummies fora do espaço de cointegração não altera a dimensão do VAR, não há alteração nos valores críticos do teste de Johansen.

11 A equação estimada pelo método de Engle-Granger tem o seguinte resultado

$\log m 1_{t}=\underset{(61,620)}{1,13166} \log$ pib- $\underset{(-10,964)}{0,3071}$ juros

onde as variáveis dummy, representando os choques referidos anteriormente, são estatisticamente significantes (exceto D7, que representa a mudança cambial em fevereiro de 1999) em níveis inferiores a 5\%. 
Artigo original

Hegemonia - Revista Eletrônica de Relações Internacionais do Centro Universitário Unieuro

ISSN: $1809-1261$

UNIEURO, Brasília, número Especial, 2016, pp. -.

Figura 2

Resíduos da Equação $\log m 1:$ 1980-2010

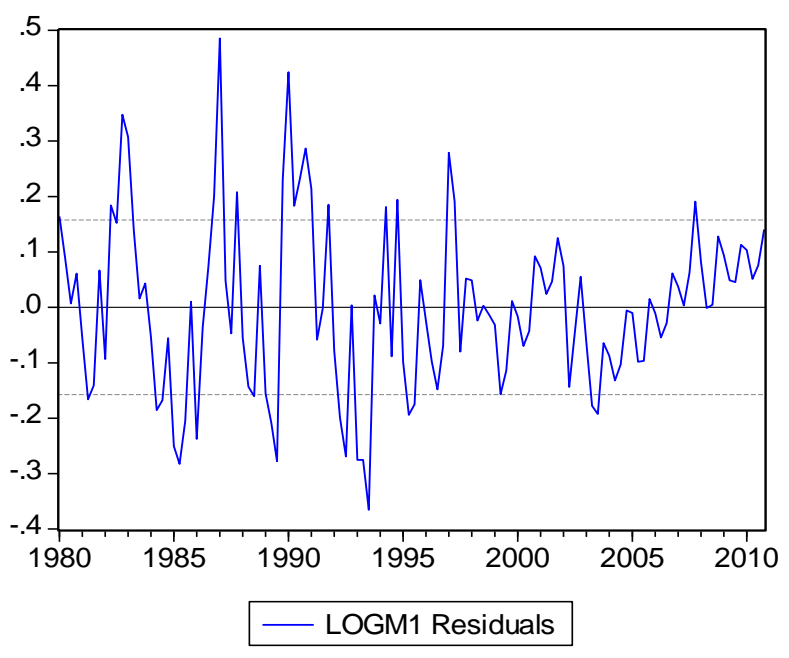

Adicionalmente, para estimar a relação de curto prazo, necessitamos incorporar uma variável que integre as dinâmicas de curto e longo prazos. Para isso, a literatura sugere a utilização de um mecanismo de correção de erros (MCE), que pode ser obtido a partir dos resíduos da equação estimada pelo método de Engle-Granger [GOLDFELD \& SICHEL (1990)]. Uma interpretação do funcionamento de tal mecanismo sugere que o ajustamento na frequência de monitoramento (ou o ajustamento nos custos de transação) descrito no modelo Baumol-Tobin deve ser considerado como uma resposta de longo prazo e não de curto prazo: os agentes ajustam lentamente seus respectivos pisos e tetos de saldos reais retidos, de modo que suas regras de monitoramento reagem 
Artigo original

Hegemonia - Revista Eletrônica de Relações Internacionais do Centro Universitário Unieuro

ISSN: $1809-1261$

UNIEURO, Brasília, número Especial, 2016, pp. -.

lentamente às mudanças nos custos e benefícios relativos da retenção de saldos reais [AKERLOF (1982)].

A estimação da relação de curto prazo com um mecanismo de correção de erros (MCE), representado pelos resíduos da equação estimada pelo método Engle-Granger com um período de defasagem, aponta resultados que indicam que os sinais e as magnitudes dos parâmetros estimados estão em conformidade com o que é previsto na literatura, com as estatísticas usuais, explicitadas no Quadro 5, abaixo, sugerindo que o modelo está bem especificado.

$$
\Delta m 1_{t}=\underset{(-0,5470)}{-0,0060}+\underset{(4,4069)}{0,7270} \Delta p i b_{t}+\underset{(3,3432)}{0,4741} \Delta p i b_{t-1}-\underset{(-7,1917)}{0,2221} \Delta j u r o s_{t}-\underset{(-4,0942)}{0,3026} M C E_{t}
$$

Quadro 5

\begin{tabular}{|c|c|c|c|c|c|c|c|c|c|}
\hline & $J B$ & $L M(1)$ & $L M(2)$ & $A R C H(1)$ & $A R C H(2)$ & $\bar{R}^{2}$ & $S E$ & $D W$ & \\
\cline { 1 - 8 } Estatística & 0,9933 & 1,8733 & 0,9286 & 1,5773 & 3,0107 & 0,6139 & 0,1202 & 2,1825 & 4 \\
\cline { 1 - 7 }$p$ Valor & 0,6086 & 0,1737 & 0,3980 & 0,2117 & 0,0531 & & & & \\
\hline
\end{tabular}

Obs: $J B$ representa o teste Jaque-Bera para não normalidade; $L M$ remete ao teste correlação serial Breusch-Godfrey defasagens e $A R C H$ representa o teste para heterocedasticidade condicional.

Como passo seguinte, deve-se verificar se a equação estimada da demanda por moeda de curto prazo é estruturalmente estável. Uma forma de fazer isso é aplicando o método dos resíduos recursivos da equação estimada para verificação de quebras estruturais, cujos resultados estão sumariados na Figura 3, abaixo, o que aponta valores fora das bandas no primeiro trimestre de 1986, no segundo trimestre de 
Artigo original

Hegemonia - Revista Eletrônica de Relações Internacionais do Centro Universitário Unieuro

ISSN: $1809-1261$

UNIEURO, Brasília, número Especial, 2016, pp. -.

1989 e no terceiro trimestre de 1991, sugerindo a ocorrência de quebras estruturais nos parâmetros da equação estimada. Por sua vez, tais quebras, se forem confirmadas por testes apropriados, apontam para a instabilidade temporal dos parâmetros da equação (de curto prazo) de demanda por moeda, indicando sua inviabilidade para avaliação da política monetária ou até mesmo para efetuar previsões da demanda por saldos reais pelos indivíduos.

Figura 3

Resíduos Recursivos de $\Delta m 1:$ 1980-2010

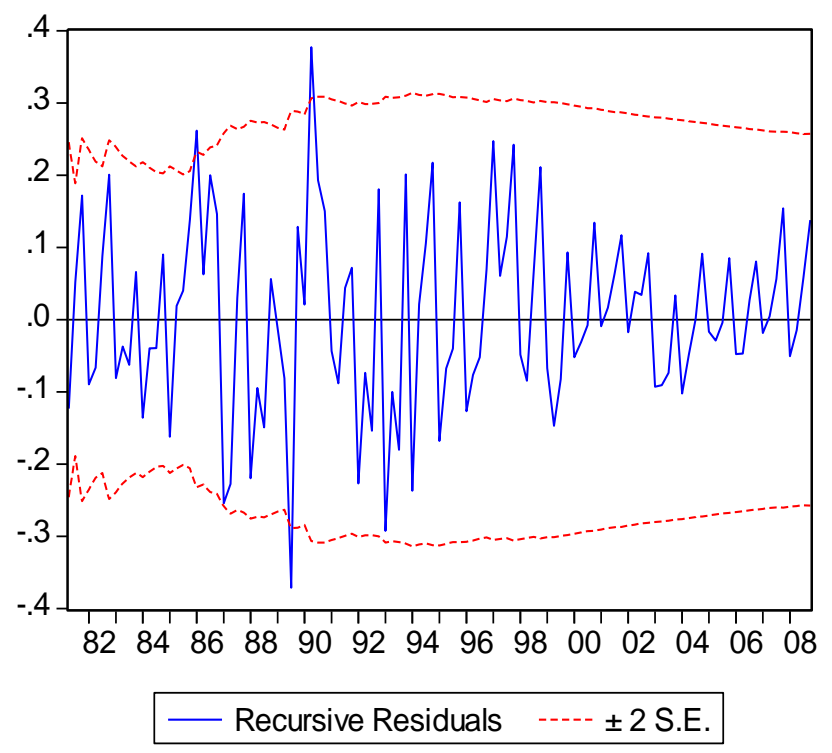

Uma forma de confirmar ou negar tais quebras é efetuando testes apropriados de exogeneidade, uma vez que há diversos tipos de exogeneidade a analisar, dependendo se o propósito do modelo é fazer inferências, fazer previsão ou analisar efeitos de mudanças de política. 
Hegemonia - Revista Eletrônica de Relações Internacionais do Centro Universitário Unieuro

ISSN: $1809-1261$

UNIEURO, Brasília, número Especial, 2016, pp. -.

A confirmação da presença de quebras estruturais apontará para a instabilidade dos parâmetros estruturais da equação de demanda por moeda no curto prazo e sua inviabilidade para analisar mudanças de política. Ainda assim, dependendo do grau de exogeneidade das variáveis que compõem tal equação, as estimativas ainda poderão ser úteis para efetuar inferências e previsões.

Para ver como isso funciona, consideremos o seguinte processo gerador de dados (DGP) bi-variado:

$$
\begin{aligned}
& y_{t}=\beta x_{t}+\varepsilon_{1 t} \\
& x_{t}=\alpha_{1} x_{t-1}+\alpha_{2} y_{t-1}+\varepsilon_{2 t}
\end{aligned}
$$

Suponhamos, como de costume, que os erros sejam normais e não correlacionados e que, além disso, o interesse situe-se na primeira equação do sistema de equações, aqui chamada de processo condicional. Em geral, o problema endereçado é se $x$ é uma variável exógena para $y$. No entanto, para ENGLE, HENDRY \& RICHARD (1983) a questão está mal definida: tudo depende dos objetivos da análise do problema. Para isso consideremos três possibilidades: (i) fazer inferências para um ou mais parâmetros de interesse; (ii) prever a variável $y$ condicionada pela variável $x$ e (iii) verificar se a primeira equação do sistema de equações é estruturalmente invariante a alterações na distribuição marginal de $x$. Cada um desses propósitos exige um tipo específico de exogeneidade, a saber: exogeneidade fraca, exogeneidade forte e exogeneidade superforte ou superexogeneidade. 
Artigo original

Hegemonia - Revista Eletrônica de Relações Internacionais do Centro Universitário Unieuro

ISSN: $1809-1261$

UNIEURO, Brasília, número Especial, 2016, pp. -.

Geralmente, uma função de densidade conjunta (aqui a função de densidade conjunta é o DGP) pode ser fatorada, de modo a ser representada como o produto de uma distribuição condicionada por uma distribuição marginal12. Suponhamos que $\lambda_{1}$ e $\lambda_{2}$ representem os parâmetros da distribuição condicionada e da distribuição marginal, respectivamente. Seja $\psi$ o conjunto de parâmetros de interesse a ser avaliado. Se as inferências sobre o conjunto de parâmetros de interesse $(\psi)$, a partir da distribuição condicional, forem equivalentes às mesmas inferências a partir da distribuição conjunta, então a distribuição marginal das variáveis condicionantes não contém informação relevante para o mesmo, podendo ser ignorada na análise. A isto chamamos exogeneidade fraca.

Tecnicamente, a análise é feita como segue. Dada a fatoração da função densidade conjunta em densidades marginal e condicionada, duas condições têm que ser satisfeitas para que se verifique a exogeneidade fraca: (a) é necessário que os parâmetros de interesse $\psi$ sejam expressos unicamente em termos dos parâmetros da distribuição condicionada, isto é, $\psi=f\left(\lambda_{1}\right)$ e que, além disso, (b) $\lambda_{1}$ e $\lambda_{2}$ possam variar livremente, onde a expressão "variar livremente" significa que não pode haver quaisquer restrições cruzadas entre $\lambda_{1}$ e $\lambda_{2}$, sendo permitido que $\lambda_{1}$ varie em função de $\lambda_{2}$, mas não $\lambda_{2}$ em função de $\lambda_{1}$.

12 Isto é, pode-se escrever a distribuição de probabilidades conjunta das variáveis aleatórias $x$ e $y$ como $f(x, y)=g(y \mid x) \cdot h(x)$, onde $g(y \mid x)$ e $h(x)=\int_{y} f(x, y) d y$ são, respectivamente, a distribuição condicionada da variável $y$ dada a variável $x$ e a distribuição marginal de $x$. 
Hegemonia - Revista Eletrônica de Relações Internacionais do Centro Universitário Unieuro

ISSN: $1809-1261$

UNIEURO, Brasília, número Especial, 2016, pp. -.

Por outro lado, enquanto o conceito de exogeneidade fraca envolve problemas de natureza estática (estimação), o conceito de exogeneidade forte envolve noções de dinâmica: em previsão, para evitar problemas de feedback entre a variável endógena $\left(y_{t}\right)$ e a variável exógena $\left(x_{t}\right)$, é necessário que a variável exógena não seja afetada pelos valores correntes e defasados da variável endógena. Assim, para que a variável $x_{t}$ do sistema de equações seja fortemente exógena para $\beta$, exige-se que, em primeiro lugar, seja fracamente exógena na determinação de $\beta$ e que, adicionalmente, $y_{t}$ não cause $x_{t}$ a la Granger.

Finalmente, para que uma variável $x_{t}$ seja superexógena, é necessário que, além de ser fracamente (ou fortemente) exógena, a equação do modelo condicional tenha parâmetros invariantes a mudanças nos parâmetros da distribuição marginal. Isto é, além de ser fracamente (ou fortemente) exógena, os parâmetros $\lambda_{1}$ tem de ser invariantes a mudanças em $\lambda_{2}$. É como se a primeira equação do sistema de equações (1) pudesse representar uma regra de decisão, descrevendo como $y$ é ajustado em resposta a $x$. Isto é, se $x$ for superexógena na determinação de $\beta$, as mudanças em $x$ não afetam a estimação de $y$.

Para realizar o teste de exogeneidade fraca, procedemos como em MADDALA (1992), segundo o qual a exogeneidade fraca das variáveis explicativas com relação aos parâmetros de interesse, pressupõe que tais variáveis sejam independentes dos resíduos da equação do processo 
Artigo original

Hegemonia - Revista Eletrônica de Relações Internacionais do Centro Universitário Unieuro

ISSN: $1809-1261$

UNIEURO, Brasília, número Especial, 2016, pp. -.

condicional, ou que os coeficientes de correlação parcial entre as mesmas sejam estatisticamente não significantes nos níveis de confiança usuais. Assim, considerando-se $\Delta m 1$ como o processo condicional, regredimos os resíduos de sua equação estimada $\left(\hat{u}_{t}\right)$, contra $\Delta$ pib $_{t}$ e $\Delta$ juros $_{t}$, cujos resultados indicam não ser possível descartar a presença de exogeneidade fraca entre as variáveis $\Delta m 1$, $\Delta p i b$ e sjuros, uma vez que os coeficientes de correlação parciais apresentam valores quase nulos e estatisticamente não significantes.

\section{Quadro 6}

Correlações Parciais entre Resíduos de $\Delta m 1$, spib e $\Delta j u r o s: 1980-2010$

\begin{tabular}{|c|c|}
\hline $\operatorname{Corr}\left(\hat{u}_{t}, \Delta\right.$ pib $)$ & $\operatorname{Corr}\left(\hat{u}_{t}, \Delta j\right.$ juros $)$ \\
\hline$-(3,09)^{-16}$ & $-(2,63)^{-15}$ \\
$(0,1314)$ & $(0,0244)$ \\
\hline
\end{tabular}

Obs: (a) Os valores entre parênteses referem-se aos desvios-padrão;

(b) $\hat{u}_{t}$ são os resíduos da equação estimada de $\Delta m 1$.

Verificada a presença de exogeneidade fraca, o próximo passo é testar a hipótese de exogeneidade forte, pelo método Granger. Se $\Delta m 1$ não causar a la Granger $\Delta p i b$ e $\Delta m 1$ não causar a la Granger $\Delta j u r o s$, então $\Delta p i b$ e $\Delta j u r o s$ serão fortemente exógenas para $\Delta m 1$. O Quadro 7, abaixo, sumaria os resultados, indicando que não se pode rejeitar a hipótese nula de que " $\Delta m 1$ não Granger causa $\Delta j u r o s "$, mas indica a rejeição da hipótese nula de que " $\Delta m 1$ não Granger causa $\Delta p i b "$ ", o que lança 
Hegemonia - Revista Eletrônica de Relações Internacionais do Centro Universitário Unieuro

ISSN: $1809-1261$

UNIEURO, Brasília, número Especial, 2016, pp. -.

dúvidas sobre o uso da equação estimada de para fazer previsão da demanda de saldos reais.

Quadro 7

Testes de Causalidade de Granger: 1980-2010

\begin{tabular}{|c|c|c|c|}
\hline Hipótese Nula & Observações & $\mathrm{F}$ & Probabilidade \\
\hline$\Delta m 1$ não Granger causa $\Delta p i b$ & 121 & 4,9234 & 0,0089 \\
\hline$\Delta m 1$ não Granger causa $\Delta j u r o s$ & 121 & 0,4448 & 0,6110 \\
\hline
\end{tabular}

Obs.: Teste com duas defasagens.

Adicionalmente, se o objetivo for a utilização das estimativas de $\Delta m 1$ para avaliação de políticas, deve-se efetuar um teste de superexogeneidade de $\Delta p i b$ e $\Delta o v e r$ sobre $\Delta m 1$, uma vez que a caracterização da superexogeneidade aponta para a superação das implicações da crítica de LUCAS (1976), segundo a qual as regras de decisão dos agentes econômicos variam com as mudanças na estrutura das séries relevantes, alterando a estrutura dos modelos econométricos. Assim, para superar tal crítica, os coeficientes estimados de uma equação têm de ser estruturalmente estáveis. Aqui, embora haja insegurança quanto à hipótese de exogeneidade forte, a análise é possível de ser aplicada, dado que a hipótese de exogeneidade fraca foi confirmada.

Uma forma simples de testar a existência de superexogeneidade, segundo HENDRY, MUELLBAUER \& MURPHY (1990), é a verificação da existência de quebras estruturais nos processos condicional e marginal, atentando-se para a coincidência temporal das mesmas. Caso haja coincidência temporal nas quebras estruturais, os parâmetros do 
Artigo original

Hegemonia - Revista Eletrônica de Relações Internacionais do Centro Universitário Unieuro

ISSN: $1809-1261$

UNIEURO, Brasília, número Especial, 2016, pp. -.

processo condicional não são constantes na amostra. É como se a quebra estrutural no modelo condicional decorresse da variabilidade dos parâmetros do modelo marginal.

Empiricamente, tal teste pode ser conduzido pela análise dos resíduos recursivos dos modelos condicional e marginal, verificando-se as possíveis coincidências temporais de quebras estruturais. Ocorrendo coincidências, a hipótese nula de invariância estrutural e, portanto, de superexogeneidade, deve ser rejeitada ${ }^{13}$.

O modelo condicional aqui utilizado é o que resulta da estimação da equação de $\Delta m 1$, cujo comportamento dos resíduos recursivos é apresentado na Figura 3. Por sua vez, os processos marginais são caracterizados por equações do tipo $\Delta p i b_{t}=f\left(\Delta m 1_{t-j}, \Delta p i b_{t-j}, \Delta j u r o s_{t-j}\right)+$ erro $_{t}$ e overe $_{t}=f\left(\Delta m 1_{t-j}, \Delta\right.$ pib $_{t-j}, \Delta$ juros $\left._{t-j}\right)+$ erro $_{t}, \quad j=1,2,3$, cujos gráficos dos resíduos recursivos são:

13 Ver CHAREMZA \& DEADMAN (1997). 
Artigo original

Hegemonia - Revista Eletrônica de Relações Internacionais do Centro Universitário Unieuro

ISSN: $1809-1261$

UNIEURO, Brasília, número Especial, 2016, pp. -.

Figura 4

Resíduos Recursivos de $\Delta p i b$ : 1980-2008

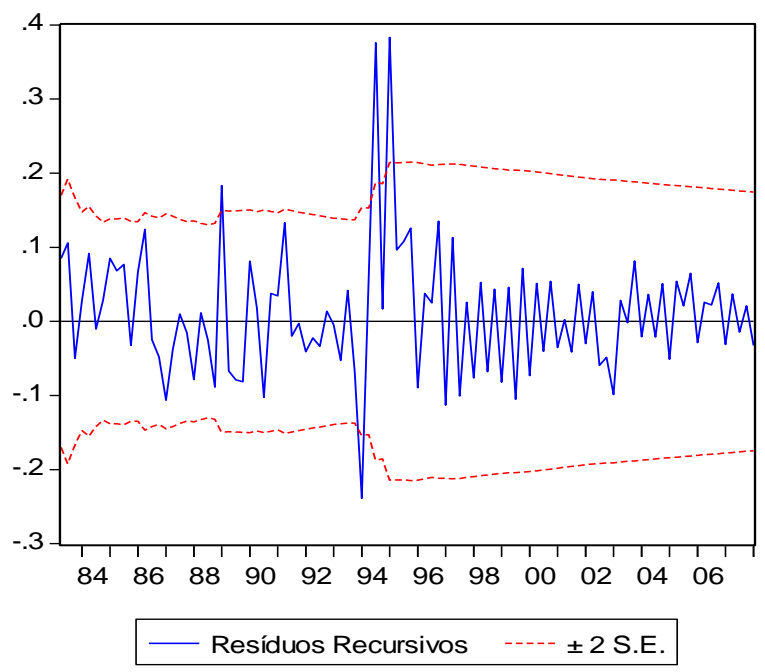

Figura 5

Resíduos Recursivos de ajuros: 1980-2008

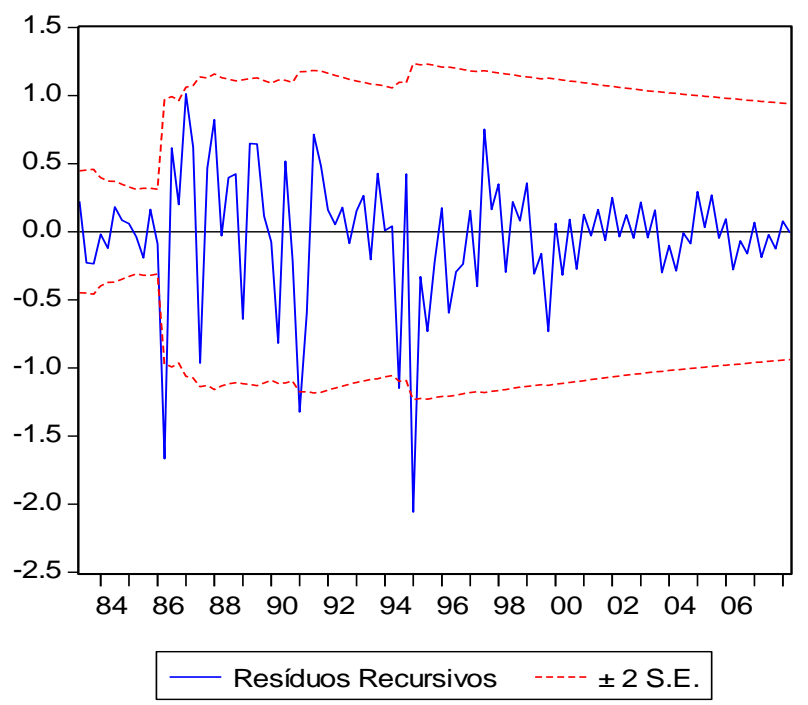


Artigo original

Hegemonia - Revista Eletrônica de Relações Internacionais do Centro Universitário Unieuro

ISSN: $1809-1261$

UNIEURO, Brasília, número Especial, 2016, pp. -.

Atente-se para o fato de que nenhum dos diagramas das figuras 4 e 5 apresentam resultados fora das bandas coincidentes com 0 correspondente no diagrama da figura 3, da equação estimada de $\Delta m 1^{14}$. Nesse caso, a equação estimada pode ser usada tanto para inferência, como modelo de avaliação de políticas.

\section{Conclusões}

Talvez uma das provas mais incontestáveis da inventividade humana seja a criação da moeda e, em particular, do conceito de moeda fiduciária. Mesmo assim, ainda que se aceite a criação da moeda como resultado da necessidade de reduzir custos de transação nas economias de troca, alguns questionamentos são pertinentes. Dentre tais questionamentos destacam-se (a) o acordo social que permite que os indivíduos aceitem com facilidade (e confiança) uma transação assimétrica, em que uma das partes recebe uma nota com custo marginal essencialmente nulo, em troca de bens ou serviços cujo custo de produção é muito superior e (b) a difícil justificação da moeda fiduciária como reserva de valor, considerando a existência de outros ativos que podem realizar função similar e proporcionar retorno positivo ao seu possuidor. Pior ainda, quando um processo inflacionário corrói o poder de compra da moeda e, mesmo assim, indivíduos racionais a aceitam, sugerindo que desejam reter um ativo arriscado e com retorno

14 Na Figura 4 os valores fora das bandas ocorrem no primeiro e no segundo trimestres de 1994 e no primeiro trimestre de 1995, enquanto que na Figura 5 tais valores ocorrem no primeiro trimestre de 1986, no primeiro trimestre de 1990 e no primeiro trimestre de 1995. 
Hegemonia - Revista Eletrônica de Relações Internacionais do Centro Universitário Unieuro

ISSN: $1809-1261$

UNIEURO, Brasília, número Especial, 2016, pp. -.

real negativo. Todas essas são perguntas ainda sem resposta satisfatória.

Além disso, há, também, perguntas ainda a responder em nível macroeconômico. De fato, apesar de haver consenso acadêmico sobre o resultado danoso ao bem-estar, causado pela expansão monetária excessiva e pela inflação daí decorrente, não há consenso acerca da melhor abordagem do problema: o que é mais indicado para a estabilidade dos preços, o controle de agregados monetários mais estritos ou o controle da taxa de juros? Digamos que o paradigma em uso aponte que a estabilidade do nível de preços tem de ser alcançada por uma política monetária de monitoramento da taxa de juros de curto prazo. Ainda nesse caso tem-se de ter em mente que a capacidade de o Banco Central prever a evolução dos agregados monetários mais estritos é muito importante. Afinal, um dos modos pelo qual a autoridade monetária espera influir sobre a taxa de juros de curto prazo é através do monitoramento e do controle das reservas dos bancos comerciais, que é um dos componentes da base monetária. Nesse contexto, a estimação da demanda por moeda é uma ferramenta de suma importância para a autoridade monetária.

Nesse sentido, a quantificação precisa dos determinantes da demanda por moeda e de sua relação com as distintas variáveis econômicas é uma ferramenta chave para lograr uma política monetária exitosa. Talvez por isso, a estimação de modelos de demanda por moeda sempre tenha sido tão popular, embora os resultados obtidos nas décadas de 1970 e 1980 não tenham sido tão satisfatórios, fato que justifica as 
Hegemonia - Revista Eletrônica de Relações Internacionais do Centro Universitário Unieuro

ISSN: $1809-1261$

UNIEURO, Brasília, número Especial, 2016, pp. -.

discussões sobre o (fim do) debate teórico em economia monetária, as discussões sobre a melhor definição de moeda, sobre a melhor forma funcional, sobre a melhor variável de escala e sobre a melhor variável representativa dos custos de oportunidade de reter moeda [GOLDFELD \& SICHEL (1990)] e, mais recentemente, ao revival do conflito entre novos keynesianos e novos clássico [ALVAREZ, LUCAS \& WEBER (2001) e WOODFORD (1998 e 2003)], consubstanciado no debate acerca de qual a melhor forma de conduzir a política monetária.

A motivação desse trabalho resultou da observação da discussão frequente em economia monetária dizendo respeito ao fato de que, como os arranjos do sistema financeiro dão ensejo a novos arranjos e como tais arranjos desestabilizam a demanda por moeda, não há esperança de que exista, a qualquer tempo, demanda por moeda estável [WOODFORD (1998)]. Por isso, a abordagem tradicional da determinação do nível de preços perde o sentido, por depender da existência de uma demanda por moeda estável.

Assim, ao estimar uma equação de demanda por moeda para o Brasil, com parâmetros estruturalmente estáveis no período em que a economia mais esteve exposta a todo tipo de choques, este trabalho contextualiza-se nesse debate, afinal a existência de demanda estável por uma definição de moeda estrita, lança alguma dúvida sobre abordagens cuja aplicação decorre, em parte, da dificuldade de prever quais os saldos reais desejados pelos indivíduos. 
Hegemonia - Revista Eletrônica de Relações Internacionais do Centro Universitário Unieuro

ISSN: $1809-1261$

UNIEURO, Brasília, número Especial, 2016, pp. -.

\section{REFERÊNCIAS BIBLIOGRÁFICAS}

1. AEKRLOF, G. A. "The Short-Run Demand for Money: A New Look at an Old Problem." American Economic Review, Volume 72, Issue 2, Papers and Proceedings of Ninety-Fourth Annual Meeting of the American Economic Association, 1982.

2. ALVAREZ, F.; LUCAS, R. E., Jr.; WEBER, W. E. "Interest Rates and Inflation." American Economic Review, 91, 2001.

3. ARRAU, P.; DE GREgORIO, J. "Financial Innovation and Money Demand: Application to Chile and Mexico." Review of Economics and Statistics, Vol. 75, 1993.

4. BATTEN, D. S.; THORNTON, D. L. "M1 or M2: Which is the Better Target?" Federal Reserve Bank of St. Louis, 1983.

5. BOFINGER, P. Monetary Policy: Goals, Institution, Strategies, and Instruments. Oxford University Press, 2001.

6. CHAREMZA, W. W.; DEADMAN, D. F. "New Directions in Econometric Practice: General to Specific Modelling, Cointegration and Vector Autoregression." Edward Elgar Publishing Ltd., Cheltenham, UK, 1997

7. CLOWER, R. W. "A Reconsideration of the Microfundations of Monetary Theory". Western Economic Journal, 6, 1967. 
Hegemonia - Revista Eletrônica de Relações Internacionais do Centro Universitário Unieuro

ISSN: $1809-1261$

UNIEURO, Brasília, número Especial, 2016, pp. -.

8. ENGLE, R. F.; GRANGER, C. W. J. "Co-integration and Error Correction: Representation, Estimation and Testing." Econometrica 40, pp. 251-276, 1987.

9. ENGLE, R. F.; HENDRY, D. F.; RICHARD, J. F. "Exogeneity". Econometrica 51, pp. 277-304, 1983

10.GOLDFELD, S. M. "The Demand for Money Revisited." Brooking Papers on Economic Activity, Volume 1973, Issue 3, 1973.

11. . "The Case of the Missing Money." Brooking Papers on Economic Activity, Volume 1976, Issue 3, 1976

12. GOLDFELD, S. M.; SICHEL, D. E. "The Demand for Money." In B. Friedman e F. Hahn (eds). The Handbook of Monetary Economics, Volume 1, New York: North-Holland, 1990.

13. HENDRY, D. F.; MUELLBAUER, J. H; MURPHY, A. "The Economics of DHSY." (In) Hey, J. D. e Winch, O. (eds). A Century of Economics: 100 Years of the Royal Economic Society and the Economic Journal. Oxford; Basil Backwell, 1990.

14. HICKS, J. R. "A Suggestion for Simplifying the Theory of Money." (in) J. R. Hicks (ed) Critical Essays in Monetary Theory. Claredon Press, Oxford, 1935. 
Hegemonia - Revista Eletrônica de Relações Internacionais do Centro Universitário Unieuro

ISSN: $1809-1261$

UNIEURO, Brasília, número Especial, 2016, pp. -.

15. HOWELLS, P.; HUSSEIN, K. "The Demand for Money: Total Transaction as the Scale Variable." Economic Letters 55, 371-377, 1997.

16. IRELAND, P. N. "Endogenus Financial Innovation and the Demand for Money." Journal of Money, Credit, and Banking. Vol. 27, n. 1, 1995.

17. LAIDLER, D. E. W.. "The Quantity of Money and Monetary Policy." Bank of Canada Working Paper 99-5, 1999.

18. LUCAS, R.. E., Jr. "Econometric Policy Evaluation: a Critique." (In) Brunner, K. e Meltzer, A. H. (eds). The Phillips Curve and Labor Markets. Amsterdam: North-Holland Publishing Co, 1976.

19. . "Equilibrium in a Pure Currency Economy." Economic Inquiry, Vol. 18, 1980

20. MADALLA, G. S. "Introduction to Econometrics." $2^{\text {nd }}$ Edition. New York: Mac-Millan Publishing Company, 1992.

21. MANKIW, N. G.; SUMMERS, L. H. "Money Demand and the Effect of Fiscal Policies." Journal of Money, Credit, and Banking. Vol. 18, n. 4, 1986.

22. MATOS FILHO, J. C. "Demanda por Moeda: Abordagens Concorrentes, Resultados Semelhantes". Planejamento e Políticas Públicas 31, 2008. 
Artigo original

Hegemonia - Revista Eletrônica de Relações Internacionais do Centro Universitário Unieuro

ISSN: $1809-1261$

UNIEURO, Brasília, número Especial, 2016, pp. -.

23. SAVING, T. R. "Transactions Costs and the Demand for Money." American Economic Review 61(3), 1971.

24. SIDRAUSKI, M. "Rational Choice and Patterns of Growth in a Monetary Economy." American Economic Review, Vol. 71, n. 2, 1967.

25. WOODFORD, M. D. "Doing Without Money: Controlling Inflation in a Post-Monetary World." Review of Economic Dynamics, 1: 173-219, 1998.

26. . Interest and Prices: Foundation of a Theory of Monetary Policy. Princeton University Press: Princeton, New Jersey, USA, 2003. 